\title{
O exame médico pre-nupclal para os casamentos consanguíneos
}

\author{
(A propósito do decreto-lei n. 3.200) \\ 'A. Almeida Júnior
}

O decreto-lei n. 3.200, de 19 de abril de 1941, que dispõe sôbre a organização e proteção da família, colocou em foco, de novo, dois problemas já várias vezes debatidos entre nós: o do casamento de consanguíneos e o do exáme médico pre-nupcial. Vamos, no presente trabalho, considerar o primeiro dos dois, examinando-o à luz dos recentes conhecimentos da Genética. Quanto ao exame médico pre-nupcial, não diremos, por ora, senão aquilo que interesse à execução do referido decreto-lei.

Os casamentos consanguíneos, os costumes e as leis

E' antiquíssima, como se sabe, e está profundamente arraigada nos costumes da maioria dos povos primitivos, a proibição do casamento entre parentes próximos (1). Obedecendo a essa tradição, as mais velhas leis, como as mais modernas, mantêm o impedimento, embora divirjam no tocante ao parentesco atingido. Sem falarmos no caso da

(1) Tanito para as populações que proibem, como para a minoria que tolera ou prefere o casamento entre parentes próximos, v.EDWARd Westermarck, The History of Human Marriage, $5 .^{\mathrm{a}}$ ed, Londres, 1922, pags. 68 a 161. 
união de ascendente com descendente, ou no de irmão com irmã (em que há impedimento universal), notemos que é frequente, hoje, a proibição com referência a tio (ou tia) e sobrinha (ou sobrinho). Menos comum a relativa a primos irmãos. Excepcional a entre primos segundos (2).

Por outro lado, alargando ainda o campo das restrições legais, a vida moderna torna dia a dia mais raros os casamentos entre parentes próximos. Eis, por exemplo, uma estatística que Fritz Lenz publicou em 1938:

\section{Casamentos consanguíneos na Prússia}

Época Porcent. Epoca Porcent.

$$
\begin{aligned}
& 1875-1884 \quad \ldots .0,0,78 \quad 1905-1914 \ldots \ldots .0,43 \\
& 1885-1894 \ldots \ldots .0,62 \quad 1915-1924 \ldots \ldots .0,30 \\
& 1895-1904 \ldots \ldots .0,48 \quad 1925-1934 \ldots \ldots .0,17
\end{aligned}
$$

Os anas de 1934, 1935 e 1936, em conjunto, dão a porcentagem de 0,11. A estatística compreende: a) os casamentos entre primos irrnãos, 90\% dos casamentos consaguíneos; b) os casamentos avunculares - tio com sobrinha, tia com sobrinho - $10 \%$ dos referidos casamentos.

Os casamentos entre primos irmãos (adverte DAHLBERG) raramente terão excedido, em qualquer país, a proporção de $1 \%$; e hoje, na Europa Ocidental, representam cêrca de $0,5 \%$ dos matrimônios (3). Os casamentos avunculares (tio com sobrinha, tia com sobrinho) seriam na França, segundo Bertillon, menos de um $(0,86)$ por 1.000 ; e na Prússia (como vimos acima), cêrca de um por 1.000 .

(2) O Código de Hammurabi proibe o comércio carnal entre pai e filha (secção 154), bem como entre mãe e filho (secção 157). A Biblia (Levítico, XVIII, 6 a 17), mais exigente nas restriçôes, veda, entre outros, os casamentos avunculares. $\mathrm{Na}$ lei judáica, o tio pode casar com a sobrinha, mas não a tia com o sobrinho. Proibem os casamentos avunculares: a Inglaterra, a Suiça e todos os Estados norte-americanos (menos quatro). Proibem, mas admitem dispensas: a França, a Bélgica, a Holanda, a Suécia, o México. Admitem-no: a Alemanha, o Perú, o Uruguái, quatro Estados norte-americanos, etc. Em mais de um terço dos Estados norte-americanos é vedado também o casamento entre primas irmãos. Oklahoma impede mesmo o casamento entre primos segundos.

(3) GuNNar Dahlberg, Race, Reason and Rubbish, trad. inglesa, Londres, 1942, pa. 166. 
Em nosso país, desconhecemos dados numéricos a respeito do fenômeno: mas a impressão que se tem é de que também declinam as uniões entre primos irmãos. No que toca aos casamentos avunculares, proibidos antes pelo Código Civil, permitidos agora pela lei n. 3.200, convém sublinhar um pormenor: passada a grande celêuma de 1919, a que deu causa o projeto de Elói de Sovza e Alvaro de CarvalHo (e durante a qual o país se manifestou quase unânime contra êsse tipo de uniões), não nos consta tenha havido qualquer movimento de opinião pleiteando a revogação do impedimento. Não sendo, pois, manifesto o pendor, é de aceitar para nós, nos próximos anos de permissão legal, a proporção, no máximo, igual à da Prússia nos seis últimos decenios (1 p. 1.000), - o que fará prevêr 200 ou poucos mais casamentos avunculares por ano.

$O$ fato é que os costumes tendem a distanciar o homem, cada vez mais, da consanguinidade.

Quais os fatores dessa orientação social? Fritz Lenz (4) salienta dois. Em primeiro lugar, a maior mobilidade do homem contemporâneo, circunstância que o arrebata fàcilmente ao círculo da família e oferece-lhe, muito mais do que outrora, nas aglomerações urbanas e industriais, oportunidades de contacto com gente estranha, Em segundo lugar, a diminuição da natalidade. Por volta de 1875 , cada casal, na Prússia, tinha, em média, cinco filhos; cada rapaz, portanto, se defrontava com vinte primas. Presentemente, não há senão dois filhos por casal, donde duas primas apenas para cada moço.

$\mathrm{E}^{\prime}$ provável que venha influindo também, na acentuação do declínio, a divulgação - com todos os seus exageros das noções sôbre os perigos da consanguinidade.

\section{Observações e estatísticas}

As leis vigentes sôbre restrições matrimoniais por parentesco - espêlho mais ou menos fiel dos costumes - não

(4) J. Am. Med. Ass., 111/1674, 1938. 
têm como preocupação única, bem o sabemos, prevenir os: males eventuais da consanguinidade. Se tivessem, silenciariam a respeito das uniões entre parentes afins. Mas aqui, neste trabalho, só êsse aspecto nos interessa. Não recordaremos, por isso, as múltiplas hipóteses com que antropologistas e psicanalistas têm procurado explicar a gênese da exogamia e a repugnância pelo incesto. Nem tampouco vêm. a propósito as justificativas de ordem moral ou social invocadas por Santo Agostinho e S. Tomás. Cabe-nos simplesmente perguntar: qual o valor biológico dos produtos, nos. casamentos consanguíneos? Nascem bons ou nascem maus?

Os fatos respondem com aparente ambiguidade.

Existem, efetivamente, observações e estatísticas favoráveis à consanguinidade. Huth, Crawley, Hutçhinson, East, Jones - todos citados por Mrlton J. Rosenau (5), tanto como Davenport, mencionam resultados bons. Várias. populações primitivas, e bem assim (ao que parece) os Tártaros, os Medas, os Persas e outros povos da antiguidade preferiam os casamentos consanguíneos, sem que tivessem. revelado, por isso, sinais de decadência biológica. Dos casos individuais ocorridos em determinada família, é habitual relembrar três. Um, moderno, é o de Carlos Darwin, o eminente naturalista, o qual, desposando sua prima irmã, produzio quatro filhos de talento notável. Os outros, antigos, dizem respeito aos Faraós. Na 18. ${ }^{a}$ dinastia, fundada 1500 anos antes de Cristo, nasceram dentro de consanguinidade que hoje considerariamos incestuosa, vários soberanos de grande merecimento (6). Mais recentemente, a família de Cleópatra VII (a amante de Marco Antônio) deu, através de casamentos análogos, resultados do mesmo modo vantajosos (7).

Predominam, entretanto, os depoimentos desfavoráveis.

(5) M. J. Rosenau, Preventive Medicine and Hygiene, 5a. ed., N. Y., 1931, pag. 568.

(6) Fraser Roberts, J. A., An Introduction to Medical Genew tics, Londres 1940, pag. 69. 207.

(7) Popenoe e Johnson, Applied Eugenics, N. Y., 1925, pag. 
Em primeiro lugar estão as observações sôbre certas familias que se notabilizaram, de um lado, pela frequência da consanguinidade, e, de outro, pela alta proporção de anomalias no físico, na inteligência e no caráter: as famílias Juke, Nams, Kallikak, Zero, Dack, Ishmael, Hickories e outras, largamente contribuiram para povoar os asilos, os hospitais, as cadeias, as casas de prostituição.

Segue-se o confronto entre grupos étnicos avêssos à consanguinidade matrimonial (como os chineses), e grupos étnicos em que êsse tipo de casamento é comum (os judeus). Naqueles são raras, nestes são frequentes as anomalias hereditárias. A população de Berlim, antes da presente guerra, mostrava o contraste: entre os não-judeus havia 6 surdosmudos por 10.000 habitantes; entre os judeus a proporção era de 27 por 10.000 (8).

$\mathrm{O}$ isolamento geográfico, fator de intima consanguinidade, quase sempre se acompanha de elevada taxa de anormais. Um exemplo: a população de Listerland, outróra ilha, na Suécia (e estudada por LundBorG), apresenta porcentagem elevadíssima de defeitos constitucionais. Outro exemplo: em 1785, uma mulher, Wyanne Malone, foi morar em Charlestown, Carolina do Sul, com seus quatro filhos; uma sobrinha casou-se com um Russel; presentemente, os sobrenomes Russel e Malone são ali muito comuns, e casamentos consanguíneos realizam-se seguidamente. Nascem, entre os filhos, numerosos surdos-mudos, loucos (formas melancólicas) e indivíduos disformes (9). Observações como essas contam-se às dezenas.

A pesquiza direta e sistemática dos defeitos físicos e mentais, em relação com a consanguinidade dós genitores (como fez A. H. Huth em 1887), tem demonstrado que os

(8) BAUR, Fischer e LENz, Human Heredity (trad. inglesa), Londres, 1931, pag. 431.

(9) Paolo EnRique, L'Eredità nell'Uomo, Milão, 1924, pag. 350. Baur, Fisher e Lenz, op. cit., pag. 264. M. J. Rosenau, op. cit., pag. 568. Gates, Heredity in Man, Londres, 1929, pag. 347. 
cônjuges de parentesco natural próximo produzem, em regra, maior número de anormais (10).

Por fim, no estudo que efetuou a respeito do declínio dos casamentos consanguíneos na Prússia (e ao qual acima nos referimos), LENZ assinala que, em flagrante paralelismo com o fenômeno, houve também diminuição dos casos de surdo-mutismo (excluidos dentre êstes, pelo cálculo estatístico, aqueles pelos quais teria sido possível responsabilizar a meningite, a escarlatina e a sífilis).

A estatística, em si, não é prova científica: concomitância entre dois fenômenos não significa nexo causal. Se significasse, ficariamos, ainda assim, em tormentosa dúvida quanto aos perigos da consanguinidade. Para avaliarmos melhor a grandeza dêsses perigos, precisamos entrar na intimidade dos fatos.

\section{A EXPLICAÇÃo GENETICA}

Por que mecanismo, afinal de contas, certas estirpes consanguíneas dão produtos geralmente bons, e até ótimos? $E$ por que em outras se multiplicam os anormais?

Não importa, para tais ef eitos, o simples fato da consanguinidade. Marido e mulher podem ser parentes muito próximos (até irmãos, como sucedia entre os Egípcios ou entre os Incas) e gerar filhos magnificos. Inversamente, os anormais que nascem de certos casamentos consanguíneos, não raro nascem também de uniões entre estranhos (11). Será mesmo preferivel, ao rapaz de familia biológicamente bem dotada, casar-se com a prima-irmã, a entrar para uma família em que as doenças e defeitos hereditários são co-

(10) Baur, Fischer e LeN'z, op. cit., pag. 431.

(11) Os maus efeitos do "inbreeding", por si só, são admitidos por Baur in BAUR, Fischer e Lenz, op. cit., pag. 110 . Não o acompanham, todavia, os demais, geneticistas. O próprio BaUr reconhece que, em relação ao homem, não há comprovações dignas de crédito. Para a explicação estritamente mendelina do fenômeno, que ocorre com certa frequência nas plantas cultivadas, v. C. H. WADDINGTON, An Introduction to Modern Genetics, N. Y., 1939, pag. 317 319. 
muns. Dentro desta última família, entretanto, representam evidente perigo os casamentos consanguíneos.

Tudo depende da qualidade genética dos cônjuges; e isto, por sua vez, está em função da qualidade dos fundadores da estirpe. Na dinastia dos Faraós, na população da ilha de Smith (12), na família de Carlos Darwin, eram bons os elementos iniciais, isentos de fatores anômalos. A família Kallikak, ao contrário, ou a população de Charlestown tiveram, por infelicidade, mau comêço.

Expliquemos melhor as coisas, escolhendo para isso exemplos elementares.

Cada defeito hereditário depende, frequentemente, de um par de fatores (ou "gens") existentes na célula-ovo de que o indivíduo proveio (13). Como esta célula-ovo se constituio pela junção do espermatozóide e do óvulo, um dos "gens" do par foi fornecido pelo genitor masculino; o outro, pelo genitor feminino.

Suponhamos, por exemplo, o caso do albinismo (14). Chamemos $a$ o fator anormal responsável por êle. Dêmos ao fator correspondente, para a pigmentação normal, a designação $A$. Em determinada população haverá portadores do par $A A$ (isto é, de dois "gens" para a normalidade); e também, embora em proporção muitíssimo menor, portadores do par laa (isto é ,de dois "gens" para o albinismo). Estes últimos indivíduos apresentarão o defeito; aqueles, não.

Imaginemos que um homem normal na pigmentação $(A A)$ se une a uma mulher albina ( $\alpha a)$. Para cada filho, o homem fornecerá (mediante mecanismo fisiológico hoje perfeitamente comprovado) um dos elementos — um só! - do par $A A$, de que é portador. A mulher, igualmente, transmitirá ao filho um só $a$ do seu próprio par. Cada filho ficará, desta forma, com o par $A a$, ou seja com um "gen" para a normalidade $(A)$, e um outro $(a)$ para o albinismo.

(12) Paolo Enriques op. cit. pag. 350.

(13) Deixamos de lado, propositadamente, os casos em que a mendelização dos fatores anormais oferece maior complexidade.

(14) $O$ albinismo consiste na ausência de pigmento na pele, nos pêlos em geral, na irio, e no fundo dos olhos. Os pêlos mostram-se brancos ou amarelados; a iris, acizentada, incolor ou levemente azulada; o fundo dos olhos, avermelhado. Nascem albinos, esporádicamente, em todos os países, provindo de quaisquer raças (inclusive da raça negra). 
Serão normais, ou serão albinos êstes portadores do par Aa? A observação de numerosíssimos casos assinala que tais produtos são normais quanto à pigmentação, em nada se distinguem dos portadores do par $A A$. Isto quer dizer, em suma, que quando o fator $A$, para a normalidade, se encontra com o fator $a$, parar o albinismo, aquele prevalece. O "gen" que assim se conduz em relação ao seu companheiro de par, tem o nome de fator dominante. 0 outro, o que fica inerte na presença do dominante, é um fator recessivo. 0 dominante, portanto, produz o mesmo efeito quer quando em duplicata $(A A)$, quer quando isolado $(A a)$. 0 recessivo, êsse (salvo o caso excepcional dos caracteres ligados ao sexo), sómente atua em duplicata $(a a)$.

Consequentemente, diante de qualquer individuo de pigmentação normal, que se nos apresente, ficamos num dilema: êle tanto pode ser portador do par $A A$ (dois "gens" dominantes), como do $A a$ (um dominante e um recessivo). Em outros termos: pode ser um hibrido, um homozigoto (por ter os dois "gens" do par iguais entre si), ou um héterozigoto (os dois "gens" do par considerado diferem entre si). Mas, se o indivíduo que tivermos à nossa frente fôr um albino, não há lugar para dúvida: êle traz consigo o par de recessivos $a a$, é um homozigoto.

\section{OS PORTADORES DE RECESSIVOS}

A noção da existência de indivíduos normais no que diz respeito a determinado defeito, mas portadores de um fator hereditário para o mesmo defeito, é fundamental e fecunda.

Imagine-se que um moço normal quanto à pigmentação, mas heterozigoto (AA), se casa com uma moça igualmente normal, mas homozigota (AA). Como cada genitor fornece a cada filho um só dos elementos de cada par de fatores, eis, a seguir, as possiveis combinações genéticas dos filhos:

AA $\times$ AA (pais)

AA ou AA (filhos)

No que se refere ao albinismo, todos os produtos dêste casal serão normais, nenhum apresentará o defeito. Mas alguns (a probabilidade é de que a metade) se tornarão por- 
tadores do recessivo A. Em todo caso, esta união não oferece, quanto aos filhos, nenhum receio.

Suponha-se, porém, que o mesmo moço, ( $\mathrm{AA}_{\mathrm{A}}$ escolhe, por azar, uma moça também portadora do recessivo (AA). As possibilidades, então, passam a ser estas:

\section{AA $\mathbf{X}$ AA (pais) \\ AA AA AA AA (filhos)}

No que diz respeito à constituição do par de "gens", êsse casamento, como se vê, poderá dar três tipos de produtos (três genótipos): 1) homozigotos $\mathrm{AA}$; 2) héterozigotos AA; 3) homozigotos AA. Sabido, porém, que os genótipos AA e AA se manifestam da mesma forma (isto é, pela normalidade), dir-se-á que da referida união podem provir dois tipos aparentes (dois fenótipos): 1) filhos normais (AA e AA) ; 2) filhos albinos (AA). E a probabilidade é de que, em cada quatro filhos do casal, um seja albino.

Probabilidade - note-se bem - não significa fatalidade. Um casal, ainda que de héterozigotos para o albinismo, pode ser bastante feliz para que todos os filhos nasçam normais. Em outro casal, por desgraça, logo o primogênito, herdando de cada um dos pais justamente o recessivo A, nasce albino.

Aí está o perigo de se casarem, um com outro, portadores do mesmo recessivo anormal: o recessivo paterno e o recessivo materno podem juntar-se, por ocasião de se constituir, na célula-ovo, o patrimônio genético do filho, e êste vir a tornar-se defeituoso. É dêsse geito que em muitas famílias, depois de várias gerações inteiramente normais, surge, para desgosto de todos, um idiota ou um imbecil, um surdo-mudo ou um defeituoso da abóbada palatina, um miope profundo ou uma criatura excepcionalmente suscetível ao bócio endêmico (15).

(15) Para o que diz respeito à forma de transmissão hereditária das doenças e outras anomalias, v. Laurence H. SNYDER, $M e^{-}$ dical Genetics, Durham, North Carolina, 1941. 


\section{PROBABILIDADES INDIVIDUAIS}

Em uma cidade como São Paulo, que tem cêrca de 1.500.000 habitantes, é de admitir que existam, no tocante ao albinismo, indivíduos de três categorias genéticas (três genótipos) :

1) homozigotos AA - albinos;

2) héterozigotos $\mathrm{AA}$ - normais;

3) homozigotos AA - normais.

Os do primeiro grupo serão em número reduzido - uns 150 , se aceitarmos para nós a proporção norte-americana (1 p. 10.000) - e é bem provável que não venham a ter filhos. Deixemo-los, pois, inteiramente de lado.

Os do segundo grupo alcançam número maior. Se houver, como estamos supondo, 150 albinos (AA) na cidade de São Paulo, o cálculo estatístico indica a probabilidade de encontrarmos 200 héterozigotos ( $\mathrm{AA}_{\mathrm{A}}$ ) para cada albino (16). 0 que significa a existência, em nossa Capital, de 30.000 indivíduos de aparência inteiramente normal (no tocante à pigmentação), mas portadores do par AA. Em outros termos, em cada 50 indivíduos normais da população, tomados ao acaso, é provável que um possua o recessivo A.

Ninguém quer ter filhos albinos. Por isso, o moço que pretenda casar-se gostará de saber se, sendo êle de pigmentação normal, possui o par de "gens" AA, ou o par AA. No primeiro caso, vai tudo bem: mesmo que a sua futura esposa seja uma héterozigota, não há (como vimos acima) nenhum perige de que qualquer filho nasça albino. Entre-

(16) As probabilidades que apresentamos, a propósito dos albinos, são tiradas de J. A. Fraser Roberts - op. cit., pags. 61 e segs. No caso do albinismo, admitimos a frequência de 1 albino p. $\mathbf{1 0 0 . 0 0 0}$ habitantes, donde, mediante cálculo, 200 portadores para cada albino (desde que os casamentos se façam indiscriminadamente). Se houver em relação a qualquer anomalia hereditária, recessiva, 1 defeituoso por milhão de habitantes, os portadores serão na prōporção de 2.000 para cada defeituoso. Se 1 defeituoso por 1.000 habitantes, haverá, aproximadamente, 60 portadores para cada defeituoso. Se 1 defeituoso por 100 habitantes, 18 portadores por indivíduo defeituoso. Se 1 defeituoso por 6 habitantes, 3 portadores para cada defeituoso (L. H. SNYDER, op. cit., pag. 40). 
tanto, se êle fôr portador do recessivo A, terá, como é natural, o desejo de excluir da sua escolha qualquer moça que também o seja. Nêste passo, infelizmente, os préstimos da Genética humana se mostram reduzidos. Não possuindo por ora (como não possúi) meios diretos para verificar se certo indivíduo de aparência normal é, ou não, portador de determinado recessivo, o mais que ela oferece são "probabilidades".

Determinado moço vai casar-se. Ê êle um homozigoto para a pigmentação normal (AA), ou um portador de recessivo (AA)? Se, na cidade de São Paulo, como vimos, em cada 50 individuos normais, um é heterozigoto para o albinismo, a probabilidade de que êsse moço seja portador de A é de $1 / 50$.

Seu coração (suponhamos) vacila entre duas moças: uma pertence a familia estranha; a outra é sua prima irmã. Que risco corre êle de produzir albinos, se se casar com aquela? Qual o risco, se preferir a prima irmã?

Vejamos o casamento com a estranha. A probabilidade de êle ser portador do recessivo a corresponde (já o dissemos) a 1/50. A da moça estranha, também. Logo, a de que os dois, conjuntamente, tenham o mesmo recessivo A, é de $1 / 50 \times 1 / 50=1 / 2.500$. Se, pois, moços quaisquer escolherem noivas na população geral, é provável que em cada 2.500 casamentos realizados, um o seja entre héterozigotos para o albinismo. Mais claramente: de cada 2.500 casamentos, apenas um será capaz de produzir filhos albinos (e isto, ainda, na proporção de um albino para cada quatro filhos).

E se o moço preferir a prima irmã? Nesse caso as coisas serão um pouco diferentes. A probabilidade de ser êle um portador continuará igual a 1/50. Mas a de que a prima irmã dêle tenha os mesmos recessivos que êle é de 1/8 (17). Por isso, o risco de que os dois, conjuntamente, possuam o recessivo A para o albinismo, é de $1 / 50 \times 1 / 8=1 / 400$. Isto

(17) Para a obtenção dêsse resultado, v. Fraser Roberts, op. cit., pag. 61 . 
quer dizer, em suma, que, em cada 400 casamentos entre primos irmãos, um tem a possibilidade de produzir albinos.

$\mathrm{E}$ se os noivos forem tio e sobrinha (ou tia e sobrinho) carnais? Aí, o risco aumentará : será de $1 / 50 \times 1 / 4=1 / 200$. Em cada 200 casamentos dêste tipo, um poderá dar filhos albinos.

É evidente a diferença no risco; a não ser que, mediante algum processo digno de confiança, possamos verificar com certeza, ou com alto grau de probabilidade, que um dos noivos é isento do recessivo incriminado (18).

\section{PROBABILIDADE SOCIAIS}

O casamento consanguíneo poderá, pois, conforme o caso, ser perigoso, inócuo ou mesmo vantajoso. Perigoso, se houver probabilidade de coexistirem, nos noivos, recessivos anormais idênticos. Vantajoso, se a provável coexistência fôr (como pode suceder) de recessivos para caracteres felizes. A impossibilidade, nas condições atuais da ciência, de descobrir, pelo exame direto do individuo, se êste é, ou não, portador de determinado recessivo, obriga-nos a confiar tão só nas probabilidades.

Para o caso de defeitos raros - como o albinismo acabamos de vêr que o risco de produzir filhos defeituosos cresce sensivelmente com a aproximação do parentesco natural. Tratando-se, porém, de defeitos frequentes na população, serão tão comuns os portadores dos correspondentes recessivos, que a consanguinidade matrimonial não lhes aumenta o risco. Independentemente de qualquer exame médico (e mesmo depois de tal exame, como explicaremos abaixo), fica ao critério dos noivos escolher entre contra-

(18) Suponha-se que a condenação de um réu fica subordi. nada à sorte. $O$ juiz apresenta-lhe três caixinhas, submetendo-as à escôlha dêle. Em cada caixinha há um só bilhete condenatório, de mistura com outros, absolutórios, todos cuidadosamente enrolados. Mas uma caixinha tem 2.500 bilhetes; outra tem 400 , e a terceira tem só 200 . Se o réu fôr inteligente, saberá decidir-se, guiando-se pelo simples cálculo de probabilidades. Salvo se o aspecto exterior dos bilhetes tiver qualquer indicação denunciadora... 
riar seus recíprocos afetos (ou outros interêsses), e arriscar-se a ter filhos anormais.

Até aqui, o prejuizo avaliado no círculo restrito da família. Mas, em relação à coletividade, que é que sucederia se porventura se generalizassem os casamentos consanguíneos?

Imaginemos (com DahlberG) que, numa população, certo defeito, produzido por fatores recessivos, existe em $25 \%$ dos indivíduos, enquanto êstes se unem ao acaso. Suponhamos ainda que, nessa mesmai população, todos os casamentos passam a ser, sùbitamente, entre primos irmãos. Em que proporções aumentará, na geração seguinte, o número de indivíduos portadores do referido defeito? De $25 \%$, passará o total a ser de $26,6 \%$. Se o defeito tiver a frequência de $9 \%$, subirá para $10,3 \%$. Se, finalmente, ocorrer em $1 \%$ da população, irá a $1,6 \%$ (19). Do ponto de vista da coletividade, o prejuizo, como se vê, não será clamoroso, dado que os aumentos, respectivamente, de $1,6 \%$, $1,3 \%$ e $0,6, \%$, pouco assustam. Demais, os casamentos entre primos irmãos, longe de constituirem a totalidade das uniões matrimoniais, mostram-se, nos paises civilizados, inferiores a $1 \%$. Do ponto de vista coletivo, o perigo dessas uniões é, pois, insignificante. Os casamentos avunculares, enfim, - apenas 1 por mil dos casamentos em geral, terão, sôbre a estatística dos anormais, efeito práticamente nulo.

\section{O EXAME MEDICO PRE-NUPCIAL DA LEI N. 3.200}

A rejeição, em 1919, do projeto de ELói DE Sovza e ALvaro de Carvalho (o qual visava permitir os casamentos avunculares) fundou-se essencialmente na motivação eugênica. Vem agora, em 1941, o decreto-lei n. 3.200, e autoriza aqueles mesmos casamentos, desde que, mediante exame médico na pessoa dos nubentes, se verifique a inexistência de inconvenientes.

(19) Gun.nar Dahlberg, op. cit., pag. 165. 
Desta sequência de fatos seria lógico inferir: $\left.10^{\circ}\right)$ que o único mal receiado pelo Código Civil, nas unióes entre colaterais do terceiro grau, era a consanguinidade; $2 .^{\circ}$ ) que o exame médico, agora prescrito, seria simplesmente o de natureza genética peculiar à situação, isto é, a pesquiza de recessivos anormais, comuns aos candidatos; $3^{\circ}$ ) que o legislador brasileiro acreditaria na possibilidade de surpreender, através do exame individual, os portadores de recessivos anormais.

Três inferências igualmente precipitadas.

A proibição dos casamentos avunculares não se inspira tão só na Eugenia. Desde os tempos de Moisés, também se lhes opõem circunstâncias de ordem moral.

Demais, tudo mostra que o legislador, embora tomando por pretexto uma situação criada pela Eugenia, saiu inteiramente do programa de Francis Galton. Bastam dois argumentos para prová-lo. $\mathrm{O}$ art. $2 .^{\circ}$ da lei determina aos médicos que, depois de examinados os nubentes, afirmem "não haver inconveniente, sob o ponto de vista da saude de qualquer deles e da prole, na realização do casamento". É óbvio que o legislador brasileiro, neste passo, estava a cem léguas dos fatores recessivos, os únicos relacionados com a consanguinidade. Pensava, isto sim, nas doenças venéreas, na tuberculose, na lepra, que independem do parentesco, e que um cônjuge pode transmitír a outro. E não é só. A lei prevê impedimentos mórbidos temporários, que o tratamento médico consegue afastar (art. 2. , parágrafo $4 .^{\circ}$ ). Ora, todos sabem que não há tratamento capaz de remover do organismo qualquer dos seus fatores genéticos. Em síntese, o legislador, embora partindo da Eugenia, instalou-se em pleno território da Higiene.

Por fim, não é crível que ao autor da lei fôsse estranha a noção de que o exame individual (o único expressamente referido) é incapaz de revelar a presença de recessivos desemparceirados. Bernardo de Magalhães, discutindo o projeto de Eló de Souza e Alvaro de Carvalho, disse, em 1919: " $O$ que se sobrepõe ao problema, tornando-o sombrio e te- 
meroso... são os inevitáveis "caracteres latentes", de que já falamos e que dormitam nos recessos dos organismos, indiferentes a todas as buscas, invisiveis a todos os olhares, invioláveis a todos os contactos..." Fernando dE MAGALHÃES, perante a Academia de Medicina do Rio de Janeiro, ponderou, na mesma época: “A questão da consanguinidade mórbida, no casamento, não se pode resolver pelo exame do indivíduo..." E perante a mesma Academia, semanas depois, Eduardo Meirelles reiterou, com um exemplo concreto, o reparo do seu eminente confrade (20). Trata-se, em suma, de noção corriqueira entre os médicos, e que, com ou sem interpretação mendeliana, já penetrou nas camadas cultas da nossa sociedade.

Tudo faz crêr, assim, que o legislador de 1941, pretextando querer resolver de maneira científica o problema dos casamentos consanguíneos, enveredou propositadamente no caminho da prevenção das doenças contagiosas. Seu intuito, ao que parece, foi atrair os noivos ao consultório médico: o casamento de tios com sobrinhas serviu de chamariz...

\section{OS DOMfNIOS NOSOGRÁFICOS DA LEI}

Se se efetivarem as nossas previsões estatísticas - e se a lei 3.200 for cumprida — dar-se-ão no Brasil, d'óravante, cêrca de 200 casamentos anuais cujos nubentes se vão submeter, obrigatóriamente, ao exame médico pre-nupcial (21).

Que doenças (ou anomalias) pesquizarão os médicos encarregados de tal exame?

Haverá, segundo crêmos, duas grandes categorias: $1^{\circ}$ ) as doenças e defeitos de causa genética; $2 .^{\circ}$ ) as doenças contagiosas.

(20) Para o histórico do projeto de Elór de Souza e Alvaro de Carvalio, vêr o excelente livro de Teodolindo Castiglione. $A$ Eugenia no Direito de Família, S. Paulo, 1942, pags. 152 a 193 . Dêle extraimos as citações acima.

21) E de presumir que êsses casamentos se dêm de preferên. cia na zona rural e nos lugarejos do interior. 
Na primeira categoria, cumpre distinguir especialmente três grupos.

O grupo inicial deve abranger (menos em virtude dos termos da lei, do que por seus propósitos específicos, implícitos) as anomalias de origem recessiva, de que os noivos, embora normais, possam ser portadores coincidentes. $£$ aqui que se impõe o estudo da árvore genealógica dos dois.

O segundo grupo compreenderá as doenças e defeitos hereditários produzidos por fator dominante. No grupo anterior, pouco importava que o próprio candidato fôsse normal: o que prevalecia era a existência do caráter defeituoso na família. No caso da dominância, a situação se inverte: se o noivo (ou a noiva) estiver isento do mal, não o transmitirá, ainda que em sua família haja dêle muitos casos.

O terceiro grupo será o das anomalias hereditárias ligadas ao sexo ("sex linked"), em que a análise das possibilidades reclama particularizada cautela. Veja-se o clássico exemplo da hemofilia. O homem são, mesmo que de família hemofílica, não oferece perigo; ao passo que, em idênticas condições, a mulher (como a última czarina da Rússia) é perigosa em relação à descendência masculina (22).

A simples enumeração dos três grupos acima - da qual propositadamente excluimos os casos mais complexos - é suficiente para mostrar como deve usar de discernimento e prudência o médico que se defronte com as situações criadas pelo decreto-lei n. 3.200.

$\mathrm{E}$ aos males hereditários se somam - por fôrça da mesma lei — os da segunda categoria, isto é, os que, como as doenças venéreas, a tuberculose ou a lepra, constituem ameaça quer para a prole, quer para o outro cônjuge.

Uma e outra categoria, entretanto, serão examinadas com vagar, quando viermos ao estudo específico do exame médico pre-nupcial.

(22) Laurence Snyder (op. cit., pags. 53 e 90) refere casos em que o conhecimento da Genética evitou (ou teria evitado) aborrecimentos em questöes matrimoniais. 